\title{
Structural characterization and immune regulation of a novel polysaccharide from Maerkang Lactarius deliciosus Gray
}

\author{
SIYUAN SU ${ }^{*}$, XIANG DING ${ }^{2 *}$, LEI FU $^{1}$ and YILING HOU ${ }^{1}$ \\ ${ }^{1}$ Key Laboratory of Southwest China Wildlife Resources Conservation, College of Life Sciences, China West Normal University; \\ ${ }^{2}$ College of Environmental Science and Engineering, China West Normal University, Nanchong, Sichuan 637009, P.R. China
}

Received November 30, 2018; Accepted May 7, 2019

DOI: $10.3892 /$ ijmm.2019.4219

\begin{abstract}
The present study investigated the structural characterization and immune regulation of a novel polysaccharide from Maerkang Lactarius deliciosus Gray. Chemical methods, high performance gel permeation chromatography, fourier transform infrared spectroscopy, nuclear magnetic resonance spectrum and gas chromatography-mass spectrometry were used to characterize the polysaccharide structure. The immunomodulatory abilities of the Maerkang L. deliciosus Gray polysaccharide (LDG-M) were also investigated. LDG-M was primarily composed of $\beta$-D-glucose and $\alpha$-D-lyxose with the ratio of 2:1. The possible structure of LDG-M had a backbone of 1,6-linked- $\beta$-D-glucose and 1,4,6-linked- $\beta$-D-glucose, with branches primarily composed of one $(1 \rightarrow 4)$-linked- $\alpha$-D-lyxose residue. The immunoregulatory activity results demonstrated that LDG-M promoted the proliferation and phagocytosis of macrophages, and induced cytokine release. LDG-M also promoted the proliferation of $B$ cells by affecting the $G_{0} / G_{1}$, $\mathrm{S}$ and $\mathrm{G} 2 / \mathrm{M}$ phases. The present study introduced LDG-M as a valuable source with unique immunoregulatory properties.
\end{abstract}

\section{Introduction}

Polysaccharides are a type of polymer composed of $\geq 10$ monoor di-oligosaccharide residues coupled together with glycosidic bonds (1), and serve an important role in pharmacology and physiology (2). Polysaccharides act as barriers between the cell wall and the environment, they mediate host-pathogen interactions and form biofilm structures. In recent years, active polysaccharides have been investigated due to their immunomodulatory, antitumor, antiviral, antioxidant and hypoglycemic effects (3-5). Furthermore, active polysaccharides can regulate

Correspondence to: Professor Yiling Hou, Key Laboratory of Southwest China Wildlife Resources Conservation, College of Life Sciences, China West Normal University, 1 Shida Road, Nanchong, Sichuan 637009, P.R. China

E-mail: starthlh@126.com

Key words: Maerkang Lactarius deliciosus Gray, polysaccharide, structure elucidation, immune regulation the immune system, activate immune cells, and complement and promote cytokine formation (6).

Lactarius deliciosus Gray is a rare edible mushroom with high nutritional value that has attracted increasing attention (7). As one of the main effective components of $L$. deliciosus, its polysaccharides exhibit a broad spectrum of application, including anti-tumor activity, macrophage immunostimulant activity and B cell immunostimulant activity (8-11). Therefore, studies on the structure and biological activity of L. deliciosus polysaccharide are of great significance for the application and development of L. deliciosus treatment. In previous studies, certain water-soluble polysaccharides have been extracted and purified from the fruiting bodies of wild L. deliciosus (8-10). These studies also revealed that L. deliciosus polysaccharides exhibit immunoregulatory and anti-tumor activities (8-10). Furthermore, the polysaccharides of L. deliciosus from different habitats exhibit different structures (11). For example, L. deliciosus polysaccharide is composed of $(1 \rightarrow 6)-\alpha$-L-mannose and $(2 \rightarrow 3)$ - $\alpha$-D-xylose at a ratio of 3:1 (8), while $L$. deliciosus polysaccharide consists of $(1 \rightarrow 6)-\alpha-D-G a l,(1 \rightarrow 2,6)-\alpha-D-G a l, \rightarrow 6)-\alpha-D-G a l$ and $\rightarrow 4)-\beta-D-G l u$ in a ratio of 1:2:1:1 (11).

In the present study, Maerkang L. deliciosus Gray polysaccharide was isolated and purified using hot water extraction technology and column chromatography, respectively (12-14). Chemical methods, high performance gel permeation chromatography (HPGPC), fourier transform infrared spectroscopy (FT-IR), nuclear magnetic resonance spectrum (NMR) and gas chromatography-mass spectrometry (GC-MS) were used to characterize the polysaccharide. The immunomodulatory ability of LDG-M was also investigated. To the best of our knowledge, the results of the present study provide a scientific basis for further study on the pharmacological action, structure-activity association and application of LDG-M.

\section{Materials and methods}

Chemicals. The fresh fruiting bodies of Maerkang L. deliciosus Gray were collected from Maerkang County, which lies in the Sichuan Aba Tibetan and Qiang Autonomous Prefecture. After vacuum freeze-drying, the bodies were crushed and stored at $4^{\circ} \mathrm{C}$ for use in the Key Laboratory of Southwest China Wildlife Resources Conservation, College of Life Sciences, China West Normal University, China. The fruiting bodies 
of Maerkang L. deliciosus Gray were identified by Professor Tang Zongxiang (Sichuan Agricultural University, China). The ethanol was purchased from Swancor Shanghai Fine Chemical Co., Ltd. (Shanghai, China). Sodium chloride was purchased from Sichuan Kelun Pharmaceutical Co., Ltd. (Chengdu, China). Trifluoroacetic acid (TFA), standard monosaccharide and dextran of different molecular weight were purchased from Tianjin Kermel Chemical Reagent Co., Ltd. (Tianjin, China). DEAE-cellulose column, Sephacryl S-300 gel column and Sephadex G-200 column were purchased from Beijing Solarbio Science \& Technology Co., Ltd. (Beijing, China). Cell counting kit (CCK)-8 (cat. no. CK04) was purchased from Dojindo Molecular Technologies, Inc. (Shanghai, China). PBS buffer, RPMI-1640 medium, phenol red free, $0.5 \%$ Trypsin-EDTA and fetal bovine serum (FBS) were purchased from Thermo Fisher Scientific, Inc. (Waltham, MA, USA). Mouse interleukin (IL)-6 (cat. no. M6000B) and tumor necrosis factor (TNF)- $\alpha$ (cat. no. MTA00B) ELISA kits were purchased from R\&D Systems China Co., Ltd. (Shanghai, China). Neutral red and DMSO were purchased from Sigma-Aldrich (Merck KGaA, Darmstadt, Germany). MTT was purchased from Amresco, LLC (Solon, OH, USA). Cell cycle and apoptosis analysis kit (cat. no. C1052) was purchased from Beyotime Biotechnology Co., Ltd. (Shanghai, China). The inverted fluorescence microscope was purchased from Leica Microsystems (DMI4000B, Germany). The intelligent high-efficiency centrifuge was purchased from Beckman Coulter, Inc. (Brea, CA, USA; Avanti JXN-26). The refrigerated centrifuge was purchased from Eppendorf (Hanburg, Germany; cat. no. 5418R). All analytical reagents were of analytical grade.

Extraction of the polysaccharide from Maerkang L. deliciosus Gray. The fresh fruiting bodies of Maerkang L. deliciosus Gray were washed with water, dried at $60^{\circ} \mathrm{C}$ and pulverized. The $300 \mathrm{~g}$ powder accurately weighed was boiled in water for $6 \mathrm{~h}$ and the ratio of powder and water was 1:3 $(15,16)$. The supernatant was collected by centrifugation $\left(16,670 \mathrm{x}\right.$ g for $20 \mathrm{~min}$ at $4^{\circ} \mathrm{C}$; Avanti JXN-26, Beckman Coulter, Inc.) and the precipitate was boiled in water for $6 \mathrm{~h}$ (repeated three times). All supernatants were concentrated to $300 \mathrm{ml}$. Four volumes of absolute ethanol were added to precipitate crude polysaccharides. Flocculent precipitation was collected and dried. Crude polysaccharides were weighed and dissolved with distilled water, which was performed as previously described (17). After adding the supernatant to the activated DEAE cellulose- 52 column $(2 \times 60 \mathrm{~cm})$, it was allowed them to stand for $10 \mathrm{~min}$ to fully bind. Sodium chloride solutions with different concentrations $(0.1,0.2,0.3$, $0.4,0.5 \mathrm{~mol} / \mathrm{l})$ were prepared as the mobile elution phase. After adding the mobile phase, the liquid was collected and concentrated. Phenol-sulfuric acid method was used to determine the polysaccharide as described previously (18). The eluate was purified on Sephadex G-200, then concentrated and centrifuged $\left(12,400 \mathrm{x} g\right.$ for $20 \mathrm{~min}$ at $4^{\circ} \mathrm{C} ; 5418 \mathrm{R}$; Eppendorf). Small molecules in the supernatant were removed by dialysis $(7 \mathrm{kDa})$ for $48 \mathrm{~h}$. For lyophilization, Maerkang L. deliciosus Gray polysaccharide (named LDG-M) was obtained for further analysis on its structure and bioactivities.

Determining the molecular weight of $L D G-M$. A total of $10 \mathrm{mg}$ LDG-M was dissolved in $1 \mathrm{ml}$ double distilled water, sonicated for $5 \mathrm{~min}$ and then filtered $(0.22-\mu \mathrm{m}$ pore). HPGPC was used to determine the molecular weight of LDG-M as previously described (19-21). The measured data were subjected to Empower Pro GPC software analysis (Agilent Empower Pro GPC Data Analysis Software for Agilent ChemStation; version B.01.02; Agilent Technologies Inc., Santa Clara, CA, USA) with a standard curve prepared from dextran to obtain molecular weight.

FT-IR analysis. A total of $5 \mathrm{mg}$ LDG-M and fully dry potassium bromide (KBr) were ground and mixed (22). Subsequently, the mixture was pressed and scanned in the Fourier transform infrared spectrometer at a range of $4,000-400 \mathrm{~cm}^{-1}$ as described previously (23).

$N M R$. For NMR analysis, 20 mg LDG-M was weighed and dissolved in $\mathrm{D}_{2} \mathrm{O}$ (24). The Varian Unity INOVA 400/45 (Varian Medical Systems, Inc., CA, USA) was used to detect the ${ }^{1} \mathrm{H}$ NMR spectra and ${ }^{13} \mathrm{C}$ NMR spectra, and tetramethylsilane was used as an internal standard (11).

Methylation analysis and GC-MS. Methyl iodide was used to prepare methylated polysaccharide (25). The methylated product was dried and dissolved in $2 \mathrm{M}$ TFA and hydrolyzed at $100^{\circ} \mathrm{C}$ for $6 \mathrm{~h}$. Silane reagent was added and the derivatized product was used to perform the GC-MS experiment. The temperature program was set as follows: Initial temperature maintained at $80^{\circ} \mathrm{C}$ for $3 \mathrm{~min}$, then raised to $200^{\circ} \mathrm{C}$ at a rate of $10^{\circ} \mathrm{C} / \mathrm{min}$ and maintained at $200^{\circ} \mathrm{C}$ for another $10 \mathrm{~min}$.

Cell lines and reagents. The mouse L929, B and macrophage RAW264.7 cell lines, purchased from the cell bank of the Typical Culture Preservation Committee of the Chinese Academy of Science (Shanghai, China), were cultured in RPMI-1640 medium with $10 \%$ FBS, $1 \%$ penicillin $(100 \mathrm{IU} / \mathrm{ml})$ and streptomycin $(100 \mathrm{mg} / \mathrm{l})$ in an incubator at $37^{\circ} \mathrm{C}$ with $5 \% \mathrm{CO}_{2}$.

Pharmacological evaluation for B cells and RAW264.7 cells stimulation. The pharmacological evaluation of $\mathrm{B}$ and RAW264.7 cell stimulation was examined using a CCK-8 assay (26). Cells were cultured in RPMI-1640 medium. When cells were in the logarithmic growth period, the medium was added to dilute cells. A density of $1 \times 10^{5}$ cells $/ \mathrm{ml}$ were added to 96 -well plates at $100 \mu \mathrm{l} /$ well and incubated in an incubator for $24 \mathrm{~h}$ at $37^{\circ} \mathrm{C}$ with $5 \% \mathrm{CO}_{2}$ (11). Different concentrations of LDG-M prepared using cell culture medium $(0.625,1.25$, $2.5,5,10,20 \mu \mathrm{g} / \mathrm{ml}$ ) were added to the 96 -well plates at $100 \mu \mathrm{l} / \mathrm{well}$. Furthermore, $5 \mu \mathrm{g} / \mathrm{ml}$ lipopolysaccharide (LPS) was used as positive control (27) and the cell culture medium without LDG-M was used as blank control. After incubated at $37^{\circ} \mathrm{C}$ for $24 \mathrm{~h}, 5 \mu \mathrm{l}$ of CCK- 8 reagent was added to each well and the cells were cultured for an additional $2 \mathrm{~h}$. A microplate reader was used to detect the optical density (OD) at $450 \mathrm{~nm}$. The formula used to calculate cell viability (\%) was as follows: [(Ac-As)/(Ac-Ab)] x100\%, where Ac was the absorbance of the control group, $\mathrm{Ab}$ was the absorbance of the blank group, and as was the absorbance of the experimental groups.

Pharmacological evaluation for macrophage phagocytic activity. RAW264.7 cells $\left(1 \times 10^{5}\right.$ cells $\left./ \mathrm{ml}\right)$ were seeded into 96-well plates at $100 \mu \mathrm{l} /$ well and incubated for $24 \mathrm{~h}$. 

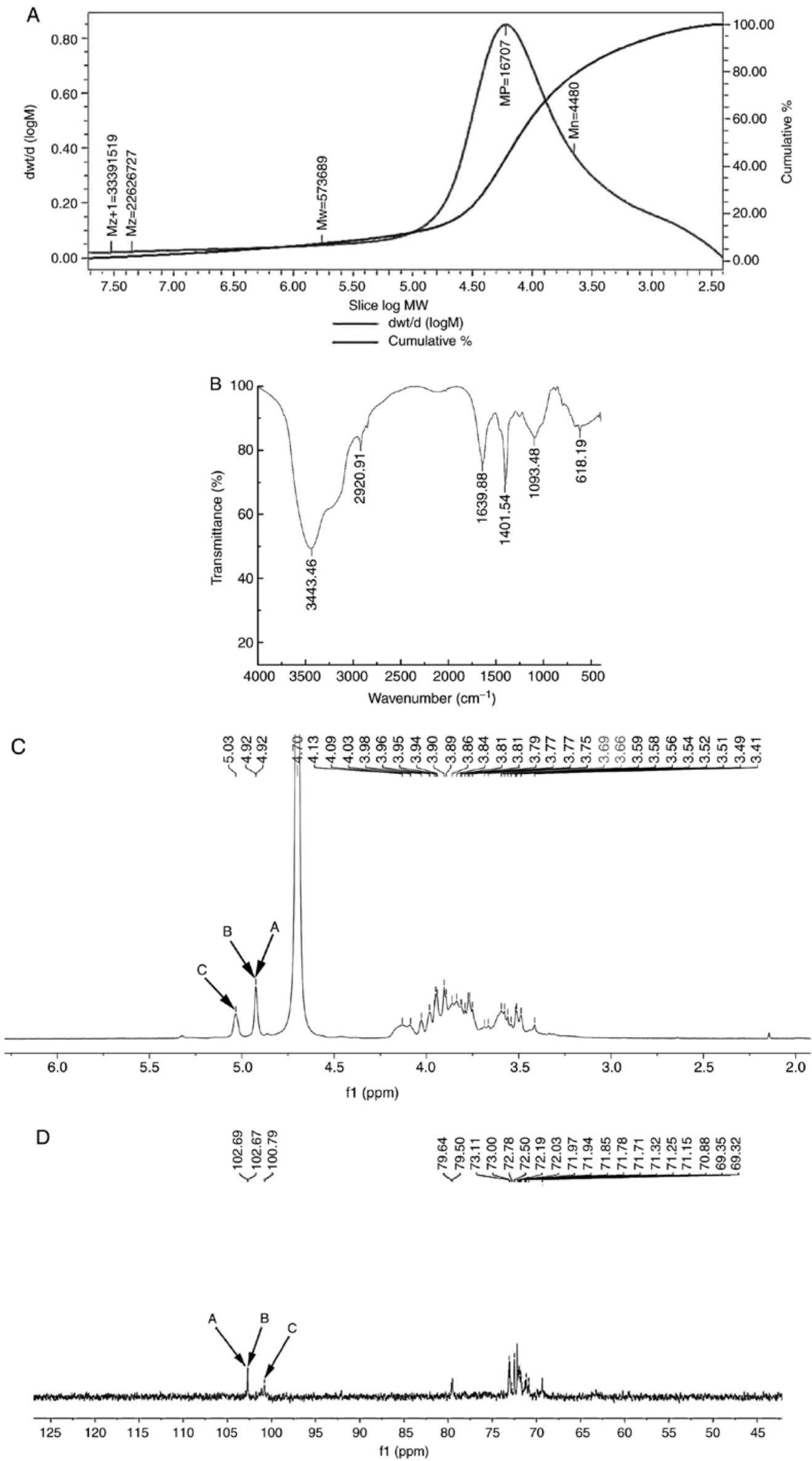

Figure 1. LDG-M Molecular weight, fourier transform infrared spectrum and 1D NMR spectrum. (A) The molecular weight of LDG-M. (B) Fourier transform infrared spectra of LDG-M. (C) The ${ }^{1} \mathrm{HNMR}$ spectra of LDG-M. (D) The ${ }^{13} \mathrm{CNMR}$ spectra of LDG-M. LDG-M, Maerkang L. deliciosus Gray polysaccharide; NMR, nuclear magnetic resonance spectrum. 
Subsequently, $100 \mu 1$ cell culture medium (blank control), LPS (final concentration $5 \mu \mathrm{g} / \mathrm{ml}$, positive control) and LDG-M solutions $(0.625,1.25,2.5,5,10,20,40 \mu \mathrm{g} / \mathrm{ml})$ were added to the 96 -well plates. After incubation at $37^{\circ} \mathrm{C}$ for $24 \mathrm{~h}$, neutral red reagent $(0.075 \mathrm{~g} / \mathrm{l})$ was added to the 96 -well plates. After $30 \mathrm{~min}$, the neutral red reagent was discarded and the cells were washed with PBS thrice, followed by the addition of $200 \mu 1$ lysis buffer (ethanol:glacial acetic acid, 1:1). The 96 -well plates were placed in an incubator for $2 \mathrm{~h}$. The OD was measured at $540 \mathrm{~nm}$.

Effect of LDG-M on the inhibitory activity of RAW264.7 macrophages on L929 tumor cells in vitro. RAW264.7 cells (effector cells, $1 \times 10^{5}$ cells $/ \mathrm{ml}$ ) and L929 cells (target cells, $1 \times 10^{6}$ cells $/ \mathrm{ml}$ ) in the logarithmic growth period were cultured on 96-well plates and incubated for $24 \mathrm{~h}$. Effector cells (RAW264.7 cells) and target cells (L929 cells) were added to 96-well plates at a ratio of 1:2 with $100 \mu \mathrm{l} /$ well. Simultaneously, separate effector and target cell groups were set at $200 \mu \mathrm{l} /$ well. When cells were adherent, supernatants were discarded. The followings groups were used: Blank control (cell culture medium), positive control (LPS $5 \mu \mathrm{g} / \mathrm{ml}$ ) and experimental (LDG-M $5 \mu \mathrm{g} / \mathrm{ml}$ ). Following an incubation at $37^{\circ} \mathrm{C}$ for $24 \mathrm{~h}$, supernatants were removed and MTT $(5 \mathrm{mg} / \mathrm{ml})$ was added at $10 \mu \mathrm{l} /$ well. The plate was then cultured in incubator at $37^{\circ} \mathrm{C}$ for $4 \mathrm{~h}$. The supernatants were discarded, and DMSO was added at $100 \mu \mathrm{l} /$ well for $15 \mathrm{~min}$. The absorbance value was measured at $570 \mathrm{~nm}$. The inhibitory activity (\%) of L929 tumor cells in the presence of macrophage RAW264.7 cells in vitro was calculated according to the following formula: [1-(OD value of experimental group-OD value of individual effector cell)/OD value of individual target cell] $\times 100 \%$.

Morphological observation of cells. Following treatment with LDG-M as aforementioned, cells were observed under a Leica inverted fluorescence microscope directly without staining (magnification, x100). Leica Application Suite X software (Leica Microsystems, Inc.; version 3.0.0.15697) was used for the assessment of cell morphology.

Evaluating cytokine levels. In order to understand the alterations in the level of cytokines, TNF- $\alpha$ and IL- 6 secreted by RAW264.7 cells, ELISA kits were used according to the manufacturers' protocols.

Effects of LDG-M on the cell cycle of B cells. Cell cycle and apoptosis analysis kit were used to evaluate the effects of LDG-M on the cell cycle of B cells. The following groups were used: Blank control, experimental (LDG-M, 2.5 and $5 \mu \mathrm{g} / \mathrm{ml}$ ) and positive control (LPS, $5 \mu \mathrm{g} / \mathrm{ml}$ ). A total of $1 \mathrm{ml}$ $70 \%$ ethanol was added to cell plates at $4^{\circ} \mathrm{C}$ for $2 \mathrm{~h}$ in order to immobilize cells. Subsequently, $0.5 \mathrm{ml}$ propidium iodide staining solution was added to each sample in a $37^{\circ} \mathrm{C}$ water bath for $30 \mathrm{~min}$. The percentages of cells at the $\mathrm{G}_{0} / \mathrm{G}_{1}, \mathrm{~S}$ and $\mathrm{G} 2 / \mathrm{M}$ phases were analyzed using a flow cytometer as previously described (28).

Statistical analysis. Data are presented as the mean \pm standard deviation. Significant differences between the experimental and control groups were analyzed using one-way ANOVA
Table I. ${ }^{13} \mathrm{C}$ NMR chemical shift data $(\delta, \mathrm{ppm})$ for LDG-M.

\begin{tabular}{lcccccc}
\hline & \multicolumn{6}{c}{ Chemical shift, $\delta(\mathrm{ppm})$} \\
\cline { 2 - 7 } Sugar residues & C1 & C2 & C3 & C4 & C5 & C6 \\
\hline 3-D-Glcp (A) & 102.69 & 71.29 & 70.88 & 72.06 & 73.00 & 69.35 \\
$\beta$-D-Glcp (B) & 102.67 & 71.71 & 79.50 & 71.27 & 72.50 & 71.11 \\
$\alpha-D-L y x p(C)$ & 100.79 & 71.78 & 72.19 & 71.15 & 72.78 & - \\
\hline
\end{tabular}

LDG-M, Maerkang L. deliciosus Gray polysaccharide; NMR, nuclear magnetic resonance spectrum; $\beta$-D-Glcp (A), 1,4,6-linked $\beta$-D-Glucopyranose; $\beta$-D-Glcp (B), 1,6-linked $\beta$-D-Glucopyranose; $\alpha$-D-Lyxp (C), 1-linked $\alpha$-D-Lyxopyranose.

followed by Student-Newman-Keuls test with SPSS 17.0 software (SPSS, Inc., Chicago, IL, USA) (27). There were six replicates in each group. $\mathrm{P}<0.05$ was used to indicate a statistically significant difference.

\section{Results}

Determining the molecular weight of $L D G-M$. HPGPC was used to evaluate the relative molecular weight of the polysaccharide, using the $\mathrm{Z}+1$-average molecular weight $(\mathrm{Mz}+1)$, $\mathrm{Z}$-average molecular weight (Mz), weight-average molecular weight (Mw), peak molecular weight $(\mathrm{Mp})$ and number-average molecular weight (Mn). The peaks of LDG-M on HPGPC were broadly symmetrical. The Mz+1 of LDG-M was $33391519 \mathrm{Da}$, Mz was 2626727 Da, Mw was 573689 Da, Mp was 16707 Da, and Mn was 4480 Da (Fig. 1A).

FT-IR analysis. The working principle of infrared spectroscopy is due to different vibration levels. According to the results for LDG-M, no absorption peak at wavelengths of 280 and $260 \mathrm{~nm}$ were present, indicating no protein and nucleic acid in the LDG-M sample. The FT-IR spectra of LDG-M displayed typical polysaccharide absorption peaks in the range of 4,000-400 $\mathrm{cm}^{-1}$ (Fig. 1B). A broad absorption peak at $3,443.46 \mathrm{~cm}^{-1}$ was designated as a $\mathrm{OH}$ stretching vibration peak, 2,920.91 $\mathrm{cm}^{-1}$ was designated as a $\mathrm{CH}$ stretching vibration peak, 1,639.88 $\mathrm{cm}^{-1}$ was designated as a $\mathrm{CO}$ stretching vibration peak, $1,401.54 \mathrm{~cm}^{-1}$ was designated as a bending vibration peak of $\mathrm{CH}_{2}, \mathrm{CH}$ and $\mathrm{OH}, 1,093.48 \mathrm{~cm}^{-1}$ was designated as a $\mathrm{CO}$ stretching vibration peak and $6,18.19 \mathrm{~cm}^{-1}$ was designated as a $\mathrm{CH}$ rocking vibration peak $(29,30)$.

Analysis of the NMR results. The proton spectrum of LDG-M is shown in Fig. 1C. In the ${ }^{1} \mathrm{H}$ NMR $(400 \mathrm{~Hz})$ spectrum, $\delta$ $5.03, \delta 4.92$ and $\delta 4.92 \mathrm{ppm}$ indicated that LDG-M had three anomeric protons, suggesting that LDG-M consisted of at least three monosaccharides. The overlapping proton signal at $\delta 4.92 \mathrm{ppm}$ was assigned to $\beta$-pyranose unit, whereas another signal at $\delta 5.03 \mathrm{ppm}$ was attributed to $\alpha$-pyranose forms (21). The proton signal for water was $\delta 4.70 \mathrm{ppm}$. The signals in $\delta$ 3.49-4.14 ppm were the proton signal of $\mathrm{H} 2-\mathrm{H} 6$ of glucose and $\mathrm{H} 2-\mathrm{H} 5$ of lyxose.

In the ${ }^{13} \mathrm{C}$ NMR spectra of LDG-M (Fig. 1D), the signals of $\delta 102.69, \delta 102.67$ and $\delta 100.79$ ppm were anomeric 

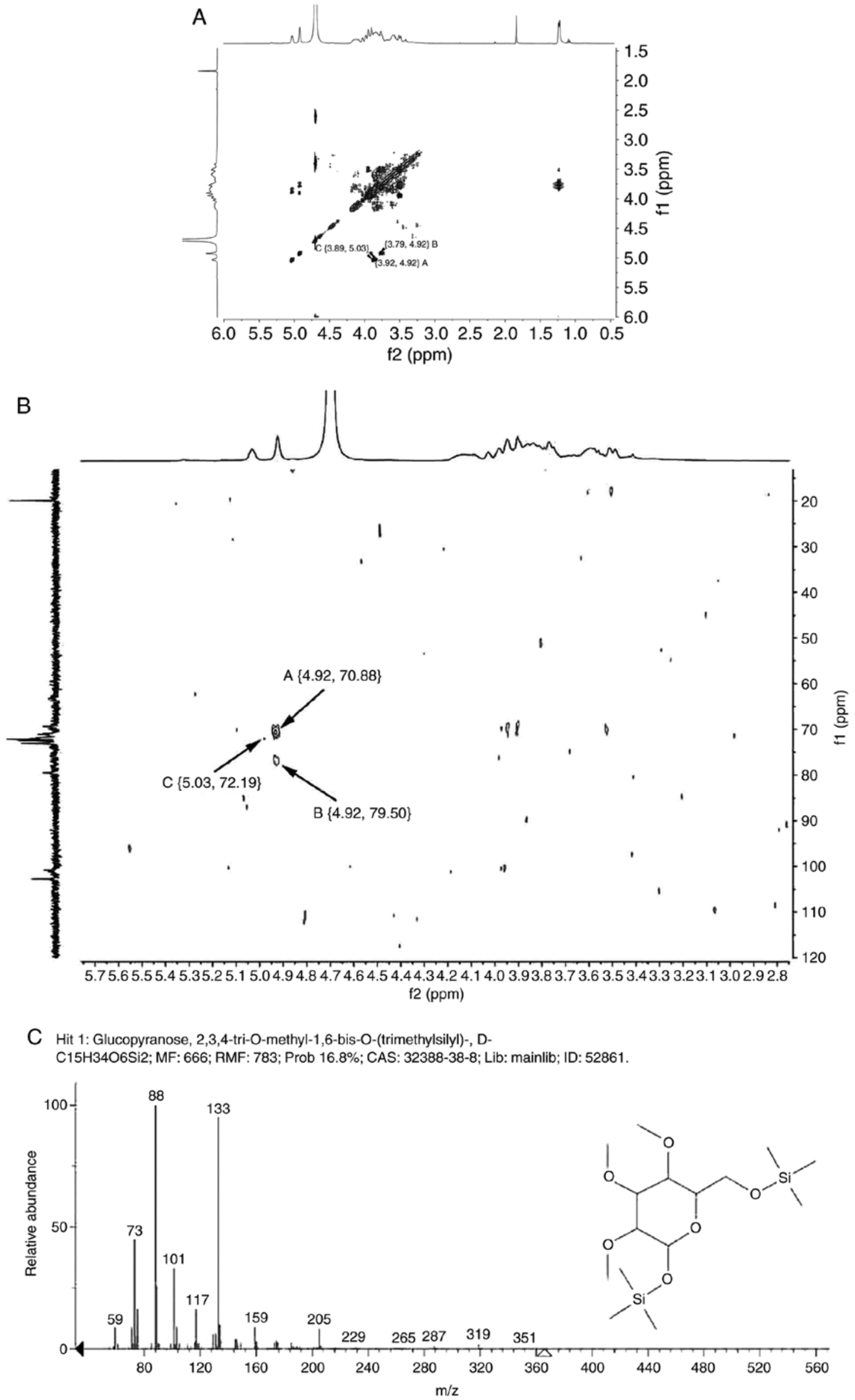

Figure 2. LDG-M 2D NMR spectrum, GC-MS fragment ion peaks and predicted chemical structure of LDG-M. (A) H-H COSY spectrum of LDG-M. (B) HMBC spectrum of LDG-M. (C) The fragment ion peaks of 2,3,4-tri-O-Me-1,6-bis-O-trimethylsilyl-Glc. 
D Hit 2: Glucopyranose, 2,3-di-O-methyl-1,4,6-tris-O-(trimethylsilyl)-

C17H40O6Si3; MF: 528; RMF: 592; Prob 6.40\%; CAS: 55400-17-4; Lib: mainlib; ID: 104526.

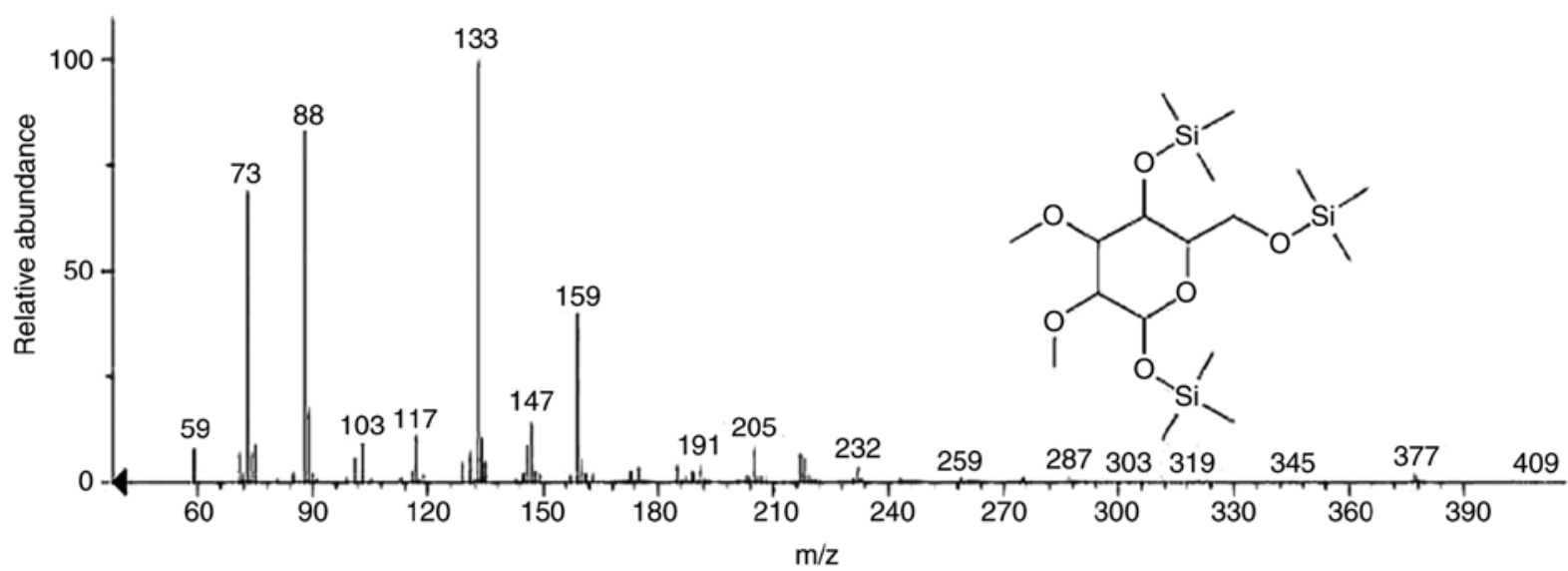

E Hit 9: Lyxopyranose, 2,3,4-tri-O-methyl-1-O-(trimethylsilyl)-

C11H24O5Si; MF: 595; RMF: 725; Prob 0.89\%; CAS: 20561-82-4; Lib: mainlib; ID: 52863
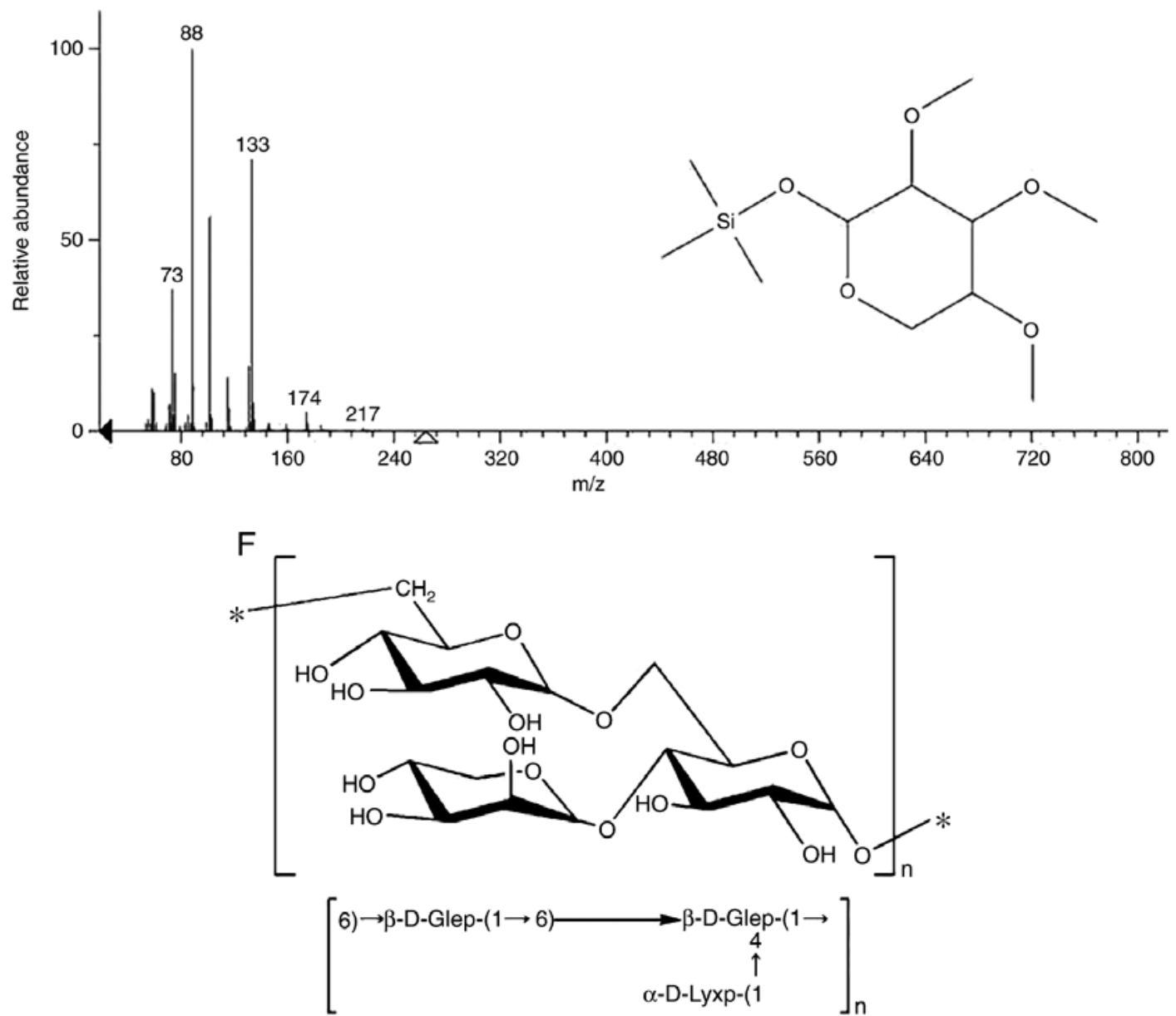

Figure 2. Continued. LDG-M 2D NMR spectrum, GC-MS fragment ion peaks and predicted chemical structure of LDG-M. (D) The fragment ion peaks of 2,3-di-O-Me-1,4,6-tris-O-trimethylsilyl-Glc. (E) The fragment ion peaks of 2,3,4-tri-O-Me-1-O-trimethylsilyl-Lyx. (F) Predicted chemical structure of LDG-M; the asterisk symbol (*) represents the connection of the same polysaccharide unit. COSY, correlated spectroscopy; HMBC, heteronuclear multiple bond correlation; GC-MS, gas chromatography-mass spectrometry.

carbon peaks, which indicated that LDG-M had $\alpha$ and $\beta$ anomeric configurations (11). It was in accord with the results of FT-IR and ${ }^{1} \mathrm{H}$ NMR. In virtue of inexistence of signals among $\delta 160-180 \mathrm{ppm}$, accordingly, no carboxyl group was present in LDG-M. Due to the absence of a chemical shift at $\delta$ 106-109 ppm, no furan ring was present in LDG-M.
According to the literature (31), the chemical shift at $\delta$ $102.69 \mathrm{ppm}$ could belong to $\mathrm{C} 1$ of residue A (1,4,6-linked $\beta$-D-Glcp), the chemical shift at $\delta 102.67 \mathrm{ppm}$ could belong to $\mathrm{C} 1$ of residue $\mathrm{B}$ (1,6-linked $\beta$-D-Glcp) and the chemical shift at $\delta 100.79 \mathrm{ppm}$ could belong to $\mathrm{C} 1$ of residue $\mathrm{C}$ (1-linked $\alpha$-D-Lyxp), respectively. The strong signals among $\delta 80-\delta$ 
Table II. GC-MS results of methylation analysis of LDG-M.

\begin{tabular}{lcc}
\hline Methylated sugar & Linkage & $\mathrm{m} / \mathrm{z}$ \\
\hline 1,6-bis-O-trimethylsilyl-Glc & $1,6-$ & 597388101117133159205229265287319351 \\
1,4,6-tris-O-trimethylsilyl-Glc & $1,4,6-$ & 597388103117133147159191205232259287303319345377409 \\
1-O-trimethylsilyl-Lyx & $1-$ & 7388133174217 \\
\hline
\end{tabular}

LDG-M, Maerkang L. deliciosus Gray polysaccharide; GC-MS, gas chromatography-mass spectrometry.

69 ppm may be assigned to the carbon signal of C2-C6 of glucose and C2-C5 of lyxose. Signals of every carbon atom are listed in Table I.

The proton chemical shift at $\delta 5.03, \delta 4.92, \delta 4.92 \mathrm{ppm}$ and a cross peak at 5.03/3.89, 4.92/3.92, 4.92/3.79 ppm were readily obtained from $\mathrm{H}-\mathrm{H}$ correlated spectroscopy (Fig. 2A), which implied that the chemical shift of $\mathrm{H} 2$ were $\delta 3.89, \delta 3.92$ and $\delta 3.79 \mathrm{ppm}$, respectively.

Long-range ${ }^{1} \mathrm{H}_{-}{ }^{13} \mathrm{C}$ heteronuclear multiple bond correlation (HMBC) spectrum was used to analyze the association between monosaccharide residues of LDG-M (Fig. 2B). A $\mathrm{H} 1 / \mathrm{C} 3$ association was identified in the ${ }^{1} \mathrm{H}-{ }^{13} \mathrm{C} \mathrm{HMBC}$ spectrum, such as $\delta 4.92 / \delta 70.88 \mathrm{ppm}$ corresponding to residue A, $\delta 4.92 / \delta 79.50 \mathrm{ppm}$ corresponding to residue $\mathrm{B}$ and $\delta 5.03 / \delta$ $72.19 \mathrm{ppm}$ corresponding to residue $\mathrm{C}$, respectively, which was consistent with the GC-MS analysis.

Analysis of GC-MS. The GC-MS results on LDG-M methylation are presented in Table II. According to the GC-MS results, it may be suggested that the fragment ion peaks of LDG-M were consistent with the data of the D-configuration monosaccharide fragment ion peaks. Therefore, the D-configuration was the configuration of glucose residues that could be determined (Fig. 2C-E). In the present study, it may be suggested that the $\beta$-D-glucosepyranose residues were 2,3,4-tri-O-methyl-1,6-bis-O-trimethysilyl-substitued and 2,3-di-O-methyl-1,4,6-tris-O-trimethysilyl-substituted and the $\alpha$-D-lyxopyranose residues were 2,3,4-tri-O-methyl-1-O-trimethysilyl-substitued (Fig. 2C-E). According to the LDG-M methylation results, the amount of $(1 \rightarrow 6)$-linked- $\beta$-D-glu cosepyranose and $(1 \rightarrow 4,6)$-linked- $\beta$-D-glucosepyranose was the highest, which constituted the main chain of the structure. In addition, the side chain was comprised of the $\alpha$-D-lyxopyranose residues. LDG-M had repeating units of a backbone of $(1 \rightarrow 6)-\beta$-D-glucosepyranose and $(1 \rightarrow 4,6)-\beta$-D-glucosepyranose, and a branch of a $(1 \rightarrow 4)-\alpha$-D-lyxopyranose residue.

On the basis of the aforementioned experimental data, the conceivable structure of LDG-M was confirmed, composing of a backbone of 1,6-linked- $\beta$-D-glucose and $1,4,6$-linked- $\beta$-D-glucose and one $(1 \rightarrow 4)$-linked- $\alpha$ D-lyxopyranose residue as a branch (Fig. 2F).

Effects of LDG-M on the proliferation of RAW264.7 cells in vitro. The results demonstrated that the LDG-M group $(0.625,1.25,2.5,5,10,20 \mu \mathrm{g} / \mathrm{ml})$ significantly promoted the proliferation of RAW264.7 cells compared with the blank control group $(\mathrm{P}<0.01)$, as shown in Fig. $3 \mathrm{~A}$. The proliferation efficiency reached the maximum with an increase of $87.8 \%$ at $5 \mu \mathrm{g} / \mathrm{ml}$ compared with the blank control group.

Effect of LDG-M on the phagocytic function of RAW264.7 cells. Neutral red is a fluorescent reagent with a large molecule and strong absorption peak at $540 \mathrm{~nm}$. As a macromolecular substance, neutral red enters macrophages only through endocytosis. Therefore, the phagocytosis of macrophages can be measured using neutral red (32). Compared with the blank control group, LDG-M significantly promoted the phagocytosis of RAW264.7 cells (Fig. 3B). At a concentration of $2.5 \mu \mathrm{g} / \mathrm{ml}$ LDG-M, the phagocytic activity reached the maximum, which was increased by $61.4 \%$ compared with that of the blank control group.

Effect of LDG-M on RAW264.7 cells secreting cytokines. Compared with the blank control group, LDG-M significantly promoted the secretion of TNF- $\alpha$ from RAW264.7 cells (Fig. 3C). When the concentration of LDG-M was $2.5 \mu \mathrm{g} / \mathrm{ml}$, the secretion of TNF- $\alpha$ reached the maximum, which was 14.4 times higher compared with that of the blank control group.

Compared with the blank control group, LDG-M significantly promoted the secretion of IL-6 from RAW264.7 cells (Fig. 3D). When the concentration of LDG-M was $5 \mu \mathrm{g} / \mathrm{ml}$, the secretion of IL- 6 reached the maximum, which was 24.5 times higher compared with that of the blank control group.

Effect of LDG-M on the inhibitory activity of RAW264.7 macrophages on L929 tumor cells in vitro. The results demonstrated that the inhibitory activity of RAW264.7 cells on L929 cells reached $49.36 \%$ at an LDG-M concentration of $5 \mu \mathrm{g} / \mathrm{ml}$, while it was $32.94 \%$ in the blank control group (Fig. 3E and F). Cell morphology observation revealed that RAW264.7 cells grew well and L929 cells grew weakly under the stimulation of LDG-M compared with the blank control group. This was consistent with the above statistical data, which confirmed that LDG-M could enhance the inhibitory activity of RAW264.7 cells on L929 cells.

Effect of LDG-M on B cells activation and B cell cycle in vitro. $B$ lymphocytes that can secrete antibodies were derived from bone marrow pluripotent stem cells and was used as a model of humoral immunity. Compared with the blank control group, the LDG-M and LPS groups significantly promoted the proliferation of B cells (Fig. 4A). At a concentration of $2.5 \mu \mathrm{g} / \mathrm{ml}$ LDG-M, the proliferation efficiency reached the maximum at $39.9 \%$. Using the Leica Microsystems inverted fluorescence microscope to observe the cell morphology and the alterations 

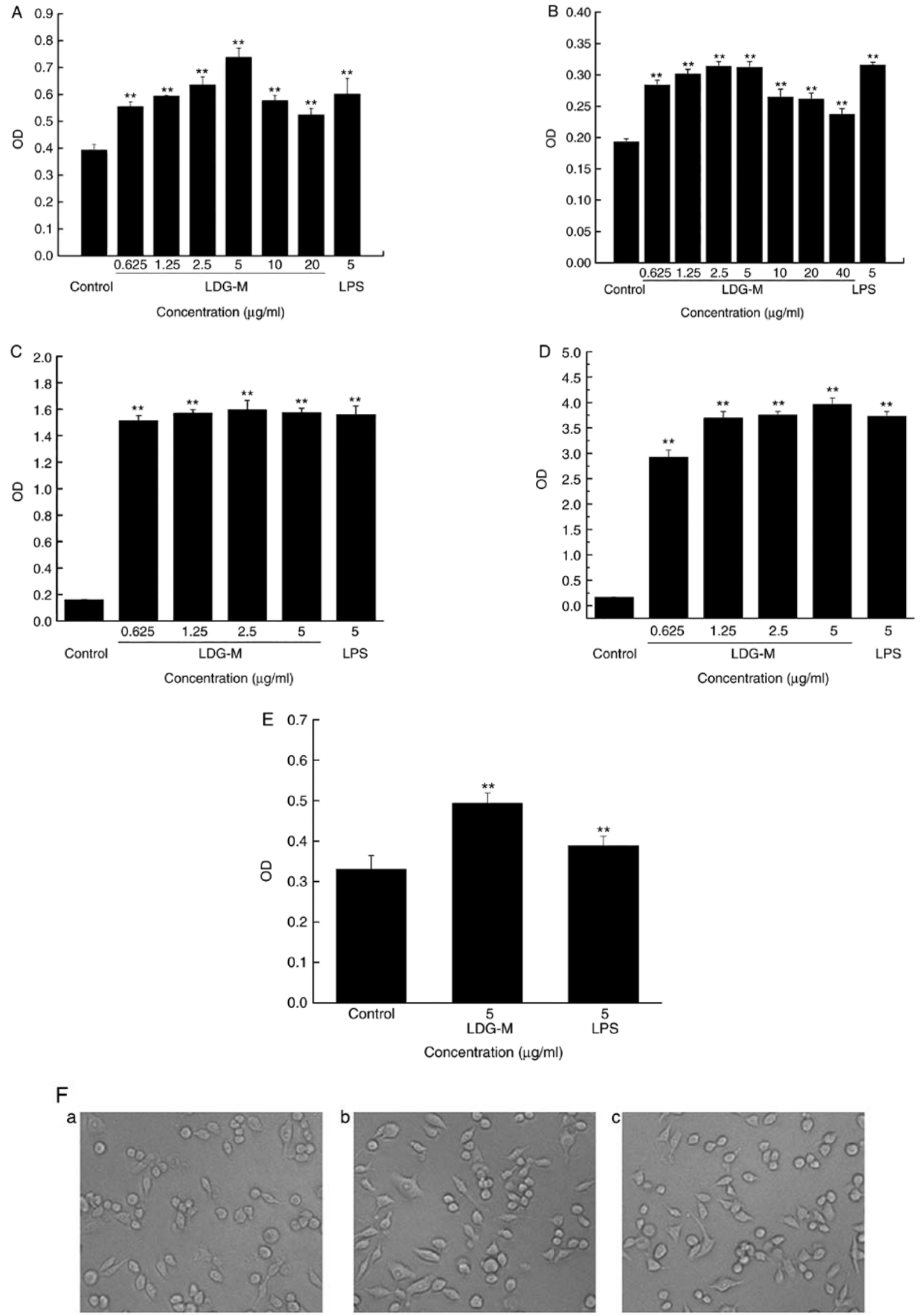

Figure 3. Effect of LDG-M on RAW264.7 cells. (A) Effects of LDG-M on the proliferation of RAW264.7 cells in vitro. (B) Effect of LDG-M on the phagocytic function of RAW264.7 cells in vitro. (C) The secretion of TNF- $\alpha$ in RAW264.7 cells stimulated by LDG-M in vitro. (D) The secretion of IL-6 in RAW264.7 cells stimulated by LDG-M in vitro. (E) Effect of LDG-M on the inhibitory activity of RAW264.7 macrophages on L929 tumor cells in vitro. (F) Cell morphological observations for the inhibitory effect of RAW264.7 macrophages (magnification, x100). a, Blank control group; b, Experimental group (LDG-M $5 \mu \mathrm{g} / \mathrm{ml}$ ); c, Positive control group (LPS $5 \mu \mathrm{g} / \mathrm{ml}$ ). ${ }^{* *} \mathrm{P}<0.01$. LDG-M, Maerkang L. deliciosus Gray polysaccharide; IL-6, interleukin-6; TNF- $\alpha$, tumor necrosis factor- $\alpha$; LPS, lipopolysaccharide. 

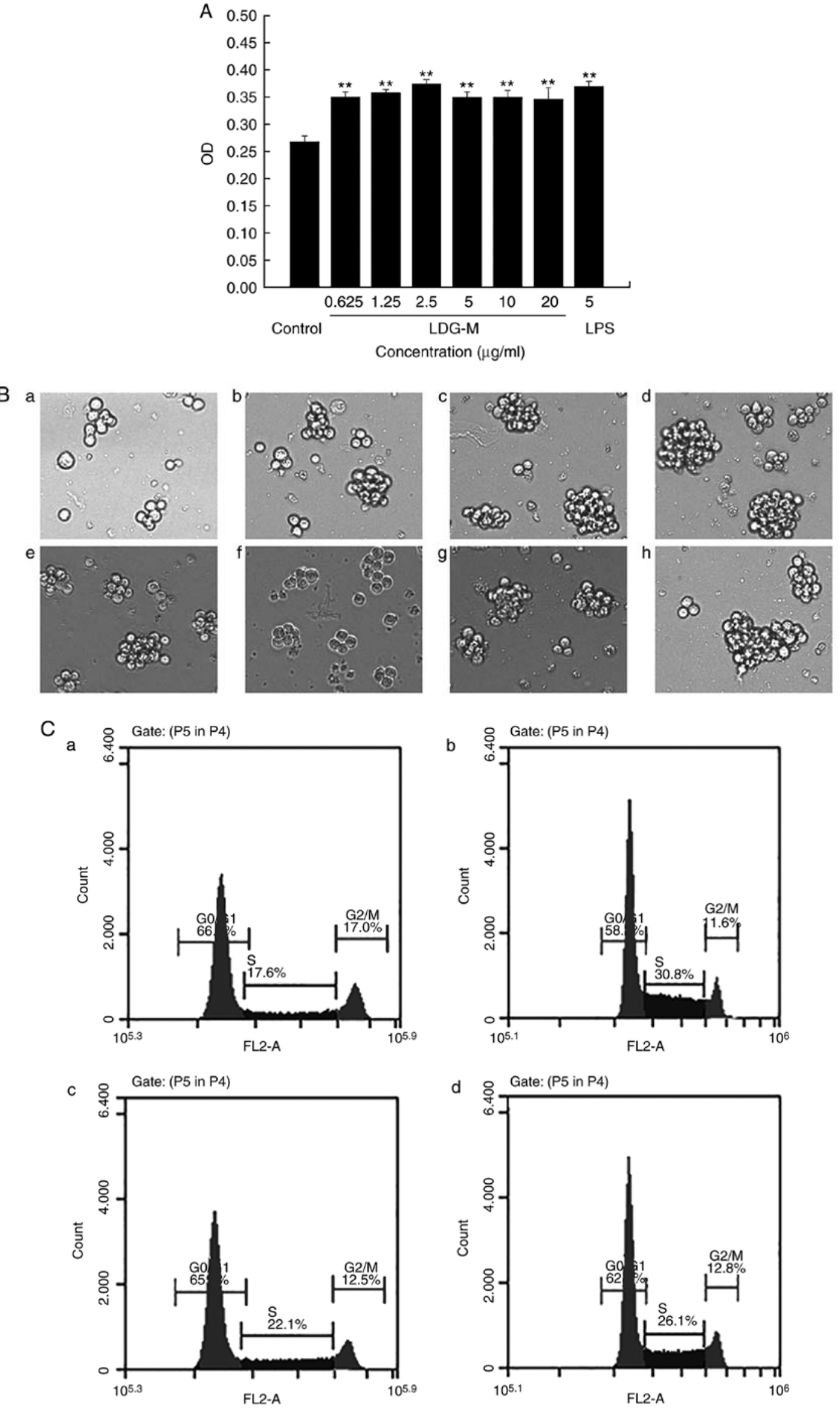

Figure 4. Effect of LDG-M on B cells. (A) Effects of LDG-M on the proliferation of B cells in vitro. (B) Cell morphological observations on the proliferation of B cells (magnification, x100). a, Blank control group; b-g, Experimental group (LDG-M 0.625, 1.25, 2.5, 5, 10, $20 \mu \mathrm{g} / \mathrm{ml}$, respectively); h, Positive control group (LPS $5 \mu \mathrm{g} / \mathrm{ml}$ ). (C) Effect of LDG-M on B cell cycle in vitro. a, Blank control group; b-c, Experimental group (LDG-M 2.5, $5 \mu \mathrm{g} / \mathrm{ml}$, respectively); d, Positive control group (LPS $5 \mu \mathrm{g} / \mathrm{ml}$ ). 


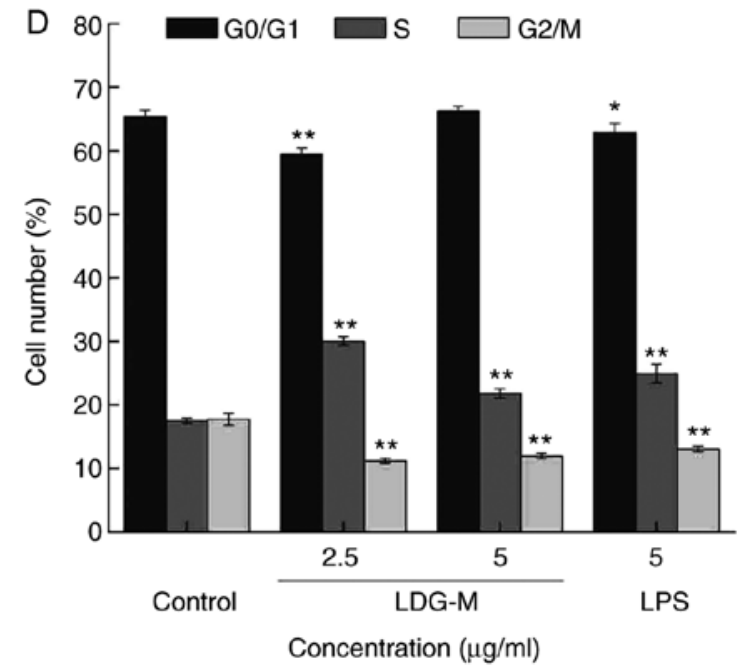

Figure 4. Continued. Effect of LDG-M on B cells. (D) Statistical analysis of LDG-M on B cell cycle in vitro. ${ }^{* *} \mathrm{P}<0.01,{ }^{*} \mathrm{P}<0.05$. LDG-M, Maerkang L. deliciosus Gray polysaccharide; LPS, lipopolysaccharide.

to cell numbers (Fig. 4B), it is evident that compared with the blank control group, the number of B cells in the LDG-M group significantly increased and were grouped together more.

Cell cycle is a process involving cell division and involves cell interphases and the cell division phase. Cells are dormant when they are in the G0 phase. Cell interphase is divided into the G1, S and G2 phases. The G1 phase involves the synthesis of RNA and ribosomes. The $\mathrm{S}$ phase includes the synthesis of DNA and histones, and in general, once the cells enter the $\mathrm{S}$ phase, cell division continues until the G1 phase of the next cycle. The G2 phase involves the mitosis preparation period when protein synthesis is completed, and the M phase is the cell division period. The results for cell cycle analysis are shown in Fig. 4C-D. LDG-M was demonstrated to promote cell cycle progression in B lymphocytes, inducing cell division. In Fig. 4D, compared with the blank control group, when the concentration of LDG-M was $2.5 \mu \mathrm{g} / \mathrm{ml}$, the number of B lymphocytes in the $\mathrm{G}_{0} / \mathrm{G}_{1}$ and $\mathrm{G} 2 / \mathrm{M}$ phases decreased significantly from 66 to $58.2 \%$, and from 17 to $11.6 \%$, respectively, while the number of cells in $\mathrm{S}$ phase increased significantly from 17.6 to $30.8 \%$. The percentage of cells in the $\mathrm{G}_{0} / \mathrm{G}_{1}$ phase was the lowest at $2.5 \mu \mathrm{g} / \mathrm{ml}$. However, when the concentration of LDG-M was $5 \mu \mathrm{g} / \mathrm{ml}$, the number of B lymphocytes in the $G_{0} / G_{1}$ phase did not change significantly. The $B$ cell cycle assay showed that when the concentration of LDG-M was $2.5 \mu \mathrm{g} / \mathrm{ml}$, the number of B cells in the $\mathrm{S}$ phase was the highest, but whether it is associated with the proliferation of $\mathrm{B}$ cells remains to be investigated.

\section{Discussion}

Maerkang L. deliciosus Gray is considered a healthy food in Asia, and demonstrates various pharmacological activities, including anticancer, antimicrobial (33), antihyperlipidemic, antifatigue, antioxidation (34) and immunological activities. Polysaccharides are involved in various biological roles, such as regulating immune function, identifying cell and cell interactions and transporting intercellular substances (35).
Additionally, polysaccharides have been used for the diagnose and treatment of cancer (36-38), with a prominent feature in enhancing host immune function $(39,40)$. Via the stimulation of immune cells, such as B lymphocytes, $\mathrm{T}$ lymphocytes, dendritic cells, macrophages and natural killer cells, polysaccharides exhibit anti-tumor effects (41). Polysaccharides in the preparation of drugs are also used as an alternative adjuvant (42).

In the present study, a novel polysaccharide was isolated from the fruiting body of Maerkang L. deliciosus Gray with a molecular weight of $573,689 \mathrm{Da}$, named LDG-M. The composition of LDG-M primarily includes $\beta$-D-glucose and $\alpha$-D-lyxose with a ratio of $2: 1$. LDG-M is composed of a backbone of 1,6-linked- $\beta$-D-glucose and $1,4,6$-linked- $\beta$-D-glucose, and branches consisting of one $(1 \rightarrow 4)$-linked- $\alpha$-D-lyxopyranose residue. Furthermore, the immunoregulatory activities results showed that LDG-M could promote the proliferation and phagocytosis of macrophages, and induce cytokine (TNF- $\alpha$ and IL-6) release. It could also significantly promote the proliferative activity of B cells and promote $B$ cells to enter $\mathrm{S}$ phase. According to macrophage proliferation, phagocytosis and cytokine secretion assays in the literature and previous reports (27,31), LPS $(5 \mu \mathrm{g} / \mathrm{ml})$ was chosen as the positive control. The combination of macrophages and L929 cells was used to assess the inhibitory effect of macrophages stimulated by the polysaccharide on tumor cells, where LPS was also used as the positive control group. LPS may slightly activate the proliferation of L929 cells; however, the experimental results showed that LDG-M significantly enhanced the inhibitory activity of RAW264.7 cells on L929 cells, which further indicated that LDG-M exhibited immunological activities.

Although the concentration of LPS used $(5 \mu \mathrm{g} / \mathrm{ml})$ was not a suitable physiological concentration and no intergroup analysis was performed, the current study was primarily performed to evaluate the effect of the polysaccharide on the proliferation of immune cells, including macrophages and B cells. Furthermore, this study aimed to investigate whether the stimulatory effect was dose-dependent in vitro rather than to identify an optimal concentration between the groups in vivo. It is also worth noting that the in vitro active concentration of the polysaccharide is different from that in vivo. Consequently, the active concentration in the current study is not suitable for use in vivo. Therefore, whether LDG-M has the corresponding biological activity in vivo and whether it is dose-dependent remains to be further studied. In short, this study introduced LDG-M as a valuable source with unique immunoregulatory properties.

\section{Acknowledgements}

Thanks to Professor Tang Zongxiang of Sichuan Agricultural University for the identification of the wild Maerkang Lactarius deliciosus Gray.

\section{Funding}

This project was supported by the Science and Technology Support Project of Sichuan Province (grant nos. 2018JY0087 and 2018NZ0055), the Cultivate Major Projects of Sichuan 
Province (grant no. 16CZ0018), Nanchong Science and Technology Bureau of Sichuan Province (grant no. 16YFZJ0043), the Talent Program of China West Normal University (grant nos. 17YC328, 17YC136 and 17YC329), the National Training Project of China West Normal University (grant no. 17c039) and the Innovative Team Project of China West Normal University (grant no. CXTD2017-3).

\section{Availability of data and materials}

All data generated or analyzed during this study are included in this published article.

\section{Authors' contributions}

YH conceived and designed the experiments of the current study. SS and LF performed the experiments and acquired data. $\mathrm{XD}$ and $\mathrm{YH}$ drafted the manuscript and revised it critically. All authors discussed the results and implications, and commented on the manuscript at all stages. All authors gave final approval of the current version to be published. Furthermore, all authors agree to be accountable for all aspects of the work in ensuring that questions associated with the accuracy or integrity of any part of the work are appropriately investigated and resolved.

\section{Ethics approval and consent to participate}

Not applicable.

\section{Patient consent for publication}

Not applicable.

\section{Competing interests}

The authors declare that there are no competing interests.

\section{References}

1. Wang M, Yang XB, Zhao JW, Lu CJ and Zhu W: Structural characterization and macrophage immunomodulatory activity of a novel polysaccharide from Smilax glabra Roxb. Carbohydr Polym 156: 390-402, 2017.

2. Yu Y, Shen MY, Song QQ and Xie J: Biological activities and pharmaceutical applications of polysaccharide from natural resources: A review. Carbohydr Polym 183: 91-101, 2018.

3. Cho CW, Han CJ, Rhee YK, Lee YC, Shin KS, Shin JS, Lee KT and Hong HD: Cheonggukjang polysaccharides enhance immune activities and prevent cyclophosphamide-induced immunosuppression. Int J Biol Macromol 72: 519-525, 2015.

4. Li N, Li L, Fang JC, Wong JH, Ng TB, Jiang Y, Wang CR, Zhang NY, Wen TY, Qu LY, et al: Isolation and identification of a novel polysaccharide-peptide complex with antioxidant anti-proliferative and hypoglycemic activities from the abalone mushroom. Biosci Rep 32: 221-228, 2012.

5. Li LJ, Li MY, Li YT, Feng JJ, Hao FQ and Lun Z: Adjuvant activity of Sargassum pallidum polysaccharides against combined newcastle disease, infectious bronchitis and avian influenza inactivated vaccines. Mar Drugs 10: 2648-2660, 2012.

6. Huang $M$, Wang FQ, Zhou XH, Yang $\mathrm{H}$ and Wang $\mathrm{Y}$ : Hypoglycemic and hypolipidemic properties of polysaccharides from Enterobacter cloacae Z0206 in KKAy mice. Carbohydr Polym 117: 91-98, 2015

7. Chen XD, Wu QX, Zhao J, Su T, Lu YM, Zhang WN, Wang Y and Chen Y: Immunomodulatory effect of a polysaccharide fraction on RAW 264.7 macrophages extracted from the wild Lactarius deliciosus. Int J Biol Macromol 128: 732-739, 2019.
8. Ding X, Hou YL and Hou WR: Structure feature and antitumor activity of a novel polysaccharide isolated from Lactarius deliciosus Gray. Carbohydr Polym 89: 397-402, 2012.

9. Hou Y, Ding X, Hou W, Song B, Wang T, Wang F and Zhong J: Immunostimulant activity of a novel polysaccharide isolated from Lactarius deliciosus (L. ex Fr.) Gray. Indian J Pharm Sci 75: 393-399, 2013.

10. Hou YL, Wang M, Zhao DQ, Liu L, Ding X and Hou W: Effect on macrophage proliferation of a novel polysaccharide from Lactarius deliciosus (L. ex Fr.) Gray. Oncol Lett 17: 2507-2515, 2019.

11. Hou YL, Liu L, Ding X, Zhao D and Hou W: Structure elucidation, proliferation effect on macrophage and its mechanism of a new heteropolysaccharide from Lactarius deliciosus Gray. Carbohydr Polym 152: 648-657, 2016.

12. Zhu Y, Ding X, Wang M, Hou Y, Hou W and Yue C: Structure and antioxidant activity of a novel polysaccharide derived from Amanita caesarea. Mol Med Rep 14: 3947-3954, 2016.

13. Ding X, Hou Y, Zhu Y, Wang P, Fu L, Zhu H, Zhang N, Qin H, Qu W, Wang F and Hou W: Structure elucidation, anticancer and antioxidant activities of a novel polysaccharide from Gomphus clavatus Gray. Oncol Rep 33: 3162-3170, 2015.

14. Ding X, Hou Y, Hou W, Zhu Y, Fu L and Zhu H: Structure elucidation and anti-tumor activities of water-soluble oligosaccharides from Lactarius deliciosus (L. ex Fr.) Gray. Pharmacogn Mag 11: 716-723, 2015.

15. Ding X, Feng S, Cao M, Li MT, Tang J, Guo CX, Zhang J, Sun Q, Yang ZR and Zhao J: Structure characterization of polysaccharide isolated from the fruiting bodies of Tricholoma matsutake. Carbohydr Polym 81: 942-947, 2010.

16. Hou Y, Ding X, Hou W, Zhong J, Zhu H, Ma B, Xu T and Li J: Anti-microorganism, anti-tumor, and immune activities of a novel polysaccharide isolated from Tricholoma matsutake. Pharmacogn Mag 9: 244-249, 2013.

17. Wang M, Jiang C, Ma L, Zhang Z, Cao L, Liu J and Zeng X: Preparation, preliminary characterization and immunostimulatory activity of polysaccharide fractions from the peduncles of Hovenia dulcis. Food Chem 138: 41-47, 2013.

18. Zhou X, Wang H, Wang B, Fu L, Yuan M, Liu J, Zhou L and Ding C: Characterization and antioxidant activities of polysaccharides from the leaves of Lilium lancifolium Thunb. Int J Biol Macromol 92: 148-155, 2016.

19. Liao W, Luo Z, Liu D, Ning Z, Yang J and Ren J: Structure characterization of a novel polysaccharide from Dictyophora indusiata and its macrophage immunomodulatory activities. J Agric Food Chem 63: 535-544, 2015.

20. Jing $\mathrm{Y}$, Huang $\mathrm{L}, \mathrm{Lv} \mathrm{W}$, Tong $\mathrm{H}$, Song $\mathrm{L}, \mathrm{Hu} \mathrm{X}$ and $\mathrm{Yu} \mathrm{R}$ : Structural characterization of a novel polysaccharide from pulp tissues of Litchi chinensis and its immunomodulatory activity. J Agric Food Chem 62: 902-911, 2014.

21. Lee JS, Synytsya A, Kim HB, Choi DJ, Lee S, Lee J, Kim WJ, Jang S and Park YI: Purification, characterization and immunomodulating activity of a pectic polysaccharide isolated from Korean mulberry fruit Oddi (Morus alba L.). Int Immunopharmacol 17: 858-866, 2013.

22. Kamnev AA, Tugarova AV, Dyatlova YA, Tarantilis PA, Grigoryeva OP, Fainleib AM and De Luca S: Methodological effects in Fourier transform infrared (FTIR) spectroscopy: Implications for structural analyses of biomacromolecular samples. Spectrochim Acta A Mol Biomol Spectrosc 193:558-564, 2018.

23. Tong H, Mao D, Zhai M,Zhang Z, Sun G and Jiang G: Macrophage activation induced by the polysaccharides isolated from the roots of Sanguisorba officinalis. Pharm Biol 53: 1511-1515, 2015.

24. van Leeuwen SS, Kuipers BJH, Dijkhuizen L and Kamerling JP: Development of a (1)H NMR structural-reporter-group concept for the analysis of prebiotic galacto-oligosaccharides of the [ $\beta$-d-Galp- $(1 \rightarrow \mathrm{x})] \mathrm{n}$-d-Glcp type. Carbohyd Res 400: 54-58, 2014.

25. Maity P, Nandi AK, Manna DK, Pattanayak M, Sen IK, Bhanja SK, Samanta S, Panda BC, Paloi S, Acharya K and Islam SS: Structural characterization and antioxidant activity of a glucan from Meripilus giganteus. Carbohydr Polym 157: 1237-1245, 2017.

26. Liu L, Jia J, Zeng G, Zhao Y, Qi X, He C, Guo W, Fan D, Han G and $\mathrm{Li} \mathrm{Z}$ : Studies on immunoregulatory and anti-tumor activities of a polysaccharide from Salvia miltiorrhiza Bunge. Carbohydr Polym 92: 479-483, 2013.

27. Zhu H, Ding X, Hou Y, Li Y and Wang M: Structure elucidation and bioactivities of a new polysaccharide from Xiaojin Boletus speciosus Frost. Int J Biol Macromol 126: 697-716, 2019. 
28. Haneef J, Parvathy M, Thankayyan RSK, Sithul H and Sreeharshan S: Bax translocation mediated mitochondrial apoptosis and caspase dependent photosensitizing effect of ficus religiosa on cancer cells. PLoS One 7: e40055, 2012.

29. Zhang W, Huang J, Wang W, Li Q, Chen Y, Feng W, Zheng D, Zhao T, Mao G, Yang L and Wu X: Extraction, purification, characterization and antioxidant activities of polysaccharides from Cistanche tubulosa. Int J Biol Macromol 93: 448-458, 2016

30. Liu J, Wen XY, Zhang XQ, Pu HM, Kan J and Jin CH: Extraction, characterization and in vitro antioxidant activity of polysaccharides from black soybean. Int J Biol Macromol 72: 1182-1190, 2015

31. Liu L, Ding X, Hou Y, Song B, Zhao D and Hou W: Structural characterization and immunological activity of a novel heteropolysaccharide from Lactikporus supharells (Fr.) murr. Latin Am J Pharm 36: 2386-2396, 2017.

32. Gomez Perez M, Fourcade L, Mateescu MA and Paquin J: Neutral Red versus MTT assay of cell viability in the presence of copper compounds. Anal Biochem 535: 43-46, 2017.

33. Dulger B, Yilmaz F and Gucin F: Antimicrobial activity of some Lactarius species. Pharm Biol 40: 304-306, 2002.

34. Fernandes Â, Antonio AL, Barreira J, Botelho L, Oliveira MB, Martins A and Ferreira I: Effects of gamma irradiation on the chemical composition and antioxidant activity of Lactarius deliciosus L. wild edible mushroom. Food Bioproc Technol 6: 2895-2903, 2013.

35. Dwek RA: Glycobiology: Toward understanding the function of sugars. Chem Rev 96: 683-720, 1996.
36. Fan S, Zhang J, Nie W, Zhou W, Jin L, Chen X and Lu J: Antitumor effects of polysaccharide from Sargassum fusiforme against human hepatocellular carcinoma HepG2 cells. Food Chem Toxicol 102: 53-62, 2017.

37. Zong A, Cao H and Wang F: Anticancer polysaccharides from natural resources: A review of recent research. Carbohydr Polym 90: 1395-1410, 2012.

38. Xie JH, Liu X, Shen MY, Nie SP, Zhang H, Li C, Gong DM and Xie MY: Purification, physicochemical characterisation and anticancer activity of a polysaccharide from Cyclocarya paliurus leaves. Food Chem 136: 1453-1460, 2013.

39. Li S, Gao A, Dong S, Chen Y, Sun S, Lei Z and Zhang Z: Purification, antitumor and immunomodulatory activity of polysaccharides from soybean residue fermented with Morchella esculenta. Int J Biol Macromol 96: 26-34, 2017.

40. Li QM, Wang JF, Zha XQ, Pan LH,Zhang HL and Luo JP: Structural characterization and immunomodulatory activity of a new polysaccharide from jellyfish. Carbohydr Polym 159: 188-194, 2017.

41. Zhang Y, Li S, Wang X, Zhang L and Cheung PCK: Advances in lentinan: Isolation, structure, chain conformation and bioactivities. Food Hydrocoll 25: 196-206, 2011.

42. Bisen PS, Baghel RK, Sanodiya BS, Thakur GS and Prasad GB: Lentinus edodes: A macrofungus with pharmacological activities. Curr Med Chem 17: 2419-2430, 2010. 